\title{
Impact of landscape dynamics and intensities on the ecological land of major cities in Ethiopia
}

\author{
Mekonnen Amberber Degefu, ${ }^{1} 2^{*}$, Mekuria Argaw ${ }^{2}$, Gudina Legese Feyisa² and Sileshi Degefa ${ }^{2}$
}

\begin{abstract}
Background: Understanding the dependence of ecological land and dynamics of the human-nature-coupled landscape is crucial for urban ecosystem resilience. In this study, we characterized and compared the Spatio-temporal responses of ecological land to urban landscape dynamics in Bahir Dar, Addis Ababa, Adama, and Hawassa cities in Ethiopia for the last three decades (1990-2020). Three sets of Landsat satellite images, field observations, and urban land indexes were used to produce landscape maps and geo-spatial data analysis.

Results: The results showed that in all cities ecological land has had changed intensely during 1990-2020 regarding its quantity, and spatial pattern. Besides, the substantial expansion of built-up ecosystems was manifested at the cost of ecological land. The built-up ecosystem was augmented by 17,341.0 ha (32.16\%), 2151.27 ha (19.64\%), 2715.21 ha (12.21\%), and 2599.65 ha (15.71\%) for Addis Ababa, Adama, Bahir Dar, and Hawassa cities respectively from 1990 to 2020 periods. A total of $40.97 \%$ of the prolonged built-up area was obtained from urban agricultural land alone. Moreover, urban sprawl is likely to continue, which will be outweighed by the loss of the open space ecosystem. The finding also confirmed the value of land-use intensity (LUI) of Addis Ababa (3.31), Bahir Dar (3.56), Hawassa (4.82), Adama (5.04) was augmented parallel with accelerated growth in the built-up ecosystems. Besides, the Integrated land-use dynamics degree (ILUDD) analysis confirmed that the spatial pattern of ecological land loss significantly consistent with LUI in all cities.

Conclusion: Land-use intensity (LUI) dynamics pattern was followed by urban ecological land to the multi-complex human-dominance ecosystem with a substantial influence on urban greenery and ecosystem services provides. Thus, in all cities, the implementation of effective ecological land management and urban planning policies are required to ensure economic development and ecosystem resilience.
\end{abstract}

Keywords: Ecological land, Landscape transitions, Cities resilience, Sustainable development

\section{Introduction}

Urbanization and associated a massive landscape change has led to a substantial change in the quantity of the composition, the structure, and the function of ecological land (Wangai et al. 2019; Liu et al. 2020a; Talukdar et al. 2020) while, boosted the formation of human-dominated or human-nature-coupled ecosystems (Zhang et al. 2013,

\footnotetext{
*Correspondence: gmekonnena@gmail.com

${ }^{1}$ Kotebe Metropolitan University, Addis Ababa, Ethiopia

Full list of author information is available at the end of the article
}

2018; Hu et al. 2019; Chen et al. 2021). During the past decades, most cities have experienced remarkable urbanrural expansion, mainly due to population growth and the migration from rural to urban areas. According to Ye et al. (2018), globally the number of people living in cities is going up a fast rate from 0.75 billion $(29.6 \%)$ in 1950 to 6.34 billion (66.7\%) projected by 2050 and demand 1.2 million $\mathrm{km}^{2}$ cityscapes by 2030 (Seto et al. 2012; Das and Das 2019). Thus, these urbanization scenarios and their inference to ecological land dynamics particularly in rapidly developing cities and surrounding ecosystems are 
becoming a common issue in policy discussions and scientific analysis (Ha et al. 2020; Mekasha et al. 2020).

In a view, accelerated urban agglomeration in megacities poses huge opportunities and objections for the sustainable development of countries. For example, megacities become the hubs of technology (Meng et al. 2020) and business activity while generating a significant amount of urban metabolic waste (Peng et al. 2017; Bahers et al. 2019; Venkata Mohan et al. 2019) and required more science and green technology-based resilient infrastructures and strategies than emerging cities (Viitanen et al. 2014). On the other hand, urbanization in the developing world depends on the conversion of ecological land to unstainable urban fabric ecosystems (Peng et al. 2017; Bahers et al. 2019). Later, created policy and institutional, socioeconomic, environmental, and technological related challenges (Ahmed et al. 2015; Kindu et al. 2015; Gashaw et al. 2018).

Moreover, the urbanization, and the land competition in the major city (Addis Ababa, Adama, Mekella, Bahir Dar, and Hawassa) and other emerging cities of Ethiopia followed a similar scenario and will continue for the next few decades due to their uncontrolled fast-growing nature (Terfa et al. 2019; Bulti and Abebe 2020; Wubie et al. 2020). In the contrast, ecological lands (the urban forest and greenery, and water bodies) were converted to impervious surfaces; like residential, industrial, and commercial systems. Generally, the rapid sprawl has created social, economic, and political instabilities that can be attributed to governance, and land use policy issues (Bhat 2017; Mohamed and Worku 2019; Das and Angadi 2020; Zou and Wang 2021).

Land dynamic studies are not new issues for Ethiopia. However, studies are mostly spatially limited and concentrated on the specific ecosystem and land-use types. For example, central highland and forest ecosystem (Kindu et al. 2015, 2016; Minta et al. 2018; Yohannes et al. 2020), Northern highlands (Tolessa et al. 2017; Temesgen et al. 2018; Gebrehiwot et al. 2020; Mekasha et al. 2020; Mekuriaw et al. 2020) and single city-based (Gashu and Gebre-Egziabher 2018; Kinfu et al. 2019; Larsen et al. 2019; Terfa et al. 2019; Bulti and Abebe 2020). Although, LULC dynamics and management vary significantly over time and from ecosystems to ecosystems. In contrast, the present study focused on the dynamics in the humanecological land nexus at different spatial and temporal scales of major active cities of Ethiopia that have not been studied before in a holistic approach. Consequently, this study aims to appraise the spatial patterns of deviations in ecological land and urban ecosystem and to evaluate to what degree the existing ecological land intervention processes and management approaches are effective in combating and controlling unsustainable dynamics in cities of Ethiopia for the implication of urban ecological land resilience.

\section{Material and methods Study areas}

The study areas fall in one metropolitan, and three regional capital cities (Addis Ababa, Hawassa, Adama, and Bahir Dar respectively) of Ethiopia (Fig. 1). These cities are among the largest and the fastest-growing urban centers of Ethiopia (Gashu and Gebre-Egziabher 2018; Terfa et al. 2020; Wubie et al. 2020). The cities are found in the central, northern, southern, and eastern parts of Ethiopia. Moreover, the cities were selected as study areas based on the following criteria (i) being the largest, a capital city or metropolitan (ii) being the main political, economic, and commercial center of their country (iii) being an active zone of industrialization and a rapid rate of the urban growth, (iv) experiencing rapid urbanization with the highest population in their respective cities of the country and (v) has relatively bettered availability of ecological land as compared to other cities in the order to maximize the probability of detecting changes in ecological land due to the urban sprawl (Gashu and GebreEgziabher 2018; Terfa et al. 2020; Wubie et al. 2020; Li et al. 2021).

Addis Ababa metropolitan: the capital city of Ethiopia and the diplomatic center of Africa. It is one of the fastest-growing cities on the continent, located at $8^{\circ} 50^{\prime} 00^{\prime \prime}-9^{\circ} 06^{\prime} 00^{\prime \prime} \mathrm{N}$ and $38^{\circ} 39^{\prime} 00^{\prime \prime}-38^{\circ} 55^{\prime} 00^{\prime \prime} \mathrm{E}$ with an average altitude of $2380 \mathrm{~m}$, and the city is covering an area of approximately $526 \mathrm{~km}^{2}$. Based on the 2007 population census the population of Addis Ababa was estimated at 3.4 million with an annual growth rate of 3.8\% (CSA 2007). Moreover, UN-HABITAT estimates that this number will continue to rise, reaching 12 million in 2024. Average daily minimum and maximum temperatures are $10.7{ }^{\circ} \mathrm{C}$ and $23.3^{\circ} \mathrm{C}$, respectively (Ethiopian Meteorology Agency, 2012), with an average of $1255 \mathrm{~mm}$ rainfall per year.

Adama city: the city is located about $100 \mathrm{~km}$ southeast of the capital Addis Ababa. It is situated at $8^{\circ} 30^{\prime}$ $0.00^{\prime \prime}-8^{\circ} 35^{\prime} 00^{\prime \prime} \mathrm{N}$, and $39^{\circ} 13^{\prime} 00^{\prime \prime}-39^{\circ} 18^{\prime} 00^{\prime \prime} \mathrm{E}$ that ranges from 1444 to 1974 m.a.s.l and covering $134.1 \mathrm{~km}^{2}$. The city found between the bottoms of an escarpment to the west, and therefore, the Great valley to the east. The average annual temperature and precipitation are $20.5{ }^{\circ} \mathrm{C}$ and $804 \mathrm{~mm}$, respectively. According to the 2007 Census of Ethiopia, this city has a total population of 220,212 with an annual growth rate of 3.8\% (CSA, 2007).

Bahir Dar is the capital city of the Amhara National Regional State, which is situated at $11^{\circ} 34^{\prime} 00^{\prime \prime}-11^{\circ} 37^{\prime} 00^{\prime \prime}$ $\mathrm{N}$ and $37^{\circ} 20^{\prime} 00^{\prime \prime}-37^{\circ} 26^{\prime} 00^{\prime \prime} \mathrm{E}$ ranges from 1717 to 2010 m.a.s.l and covering $134.1 \mathrm{~km}^{2}$. It is distanced about $578 \mathrm{~km}$ northwest of the capital city of the country. The 


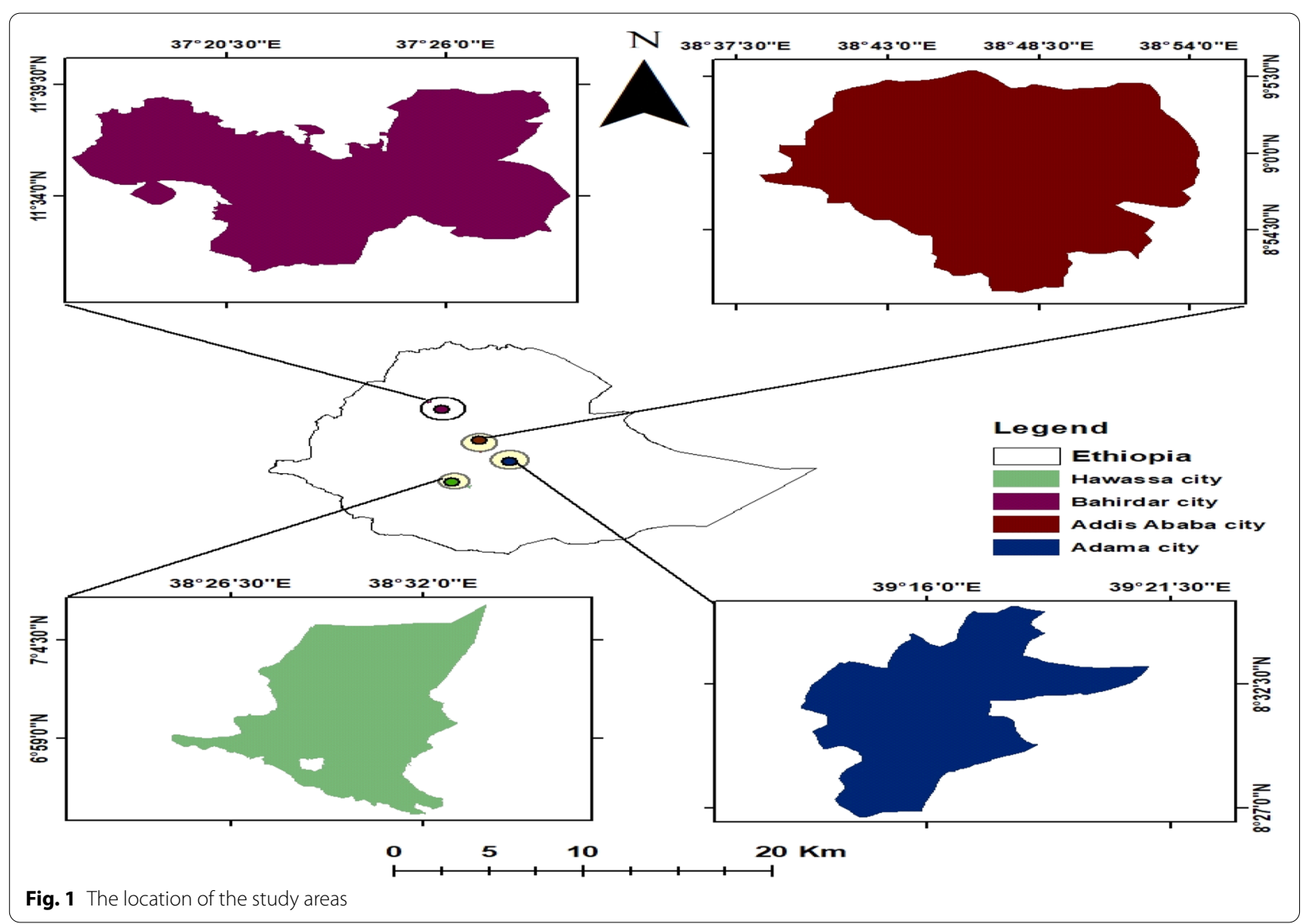

population of Bahir Dar city was 180,094 with an annual growth rate of $3.8 \%$ (CSA, 2007). Based on the projection of the 2007 census, the population was estimated to be more than eight-fold by 2040 . The mean maximum and minimum annual temperatures are $28.3{ }^{\circ} \mathrm{C}$ and $11.4{ }^{\circ} \mathrm{C}$, respectively.

Hawassa: the capital city of Sidam Regional State, which is situated at $7^{\circ} 00^{\prime} 30^{\prime \prime}-7^{\circ} 06^{\prime} 00^{\prime \prime} \mathrm{N}$ and $38^{\circ} 28^{\prime}$ $34.86^{\prime \prime}-38^{\circ} 32^{\prime} 00^{\prime \prime} \mathrm{E}$ and the average elevation of the city is 1708 m.a.s.l and it is distanced $275 \mathrm{~km}$ south of Addis Ababa. The city administration has an area of $157.2 \mathrm{Km}^{2}$. Based on 2007, census the population of Hawassa was 57,139, and estimated the population of Hawassa in 2017 to be 315,267 (CSA, 2017). Hawassa has a mean annual temperature and precipitation of $20.8{ }^{\circ} \mathrm{C}$ and $993.4 \mathrm{~mm}$ respectively (NMA, 2020). It is one of the main urban areas of Ethiopia located inside the greater Ethiopian valley.

Table 1 List of satellite data and acquisition date of the study areas

\begin{tabular}{|c|c|c|c|c|c|c|}
\hline \multirow[t]{2}{*}{ Cities } & \multirow[t]{2}{*}{ Path/row } & \multicolumn{4}{|c|}{ Image acquisition date } & \multirow[t]{2}{*}{ Source } \\
\hline & & 1990 & 2000 & 2010 & 2020 & \\
\hline Addis Ababa & $168 / 054$ & $04 / 02 / 1990^{a}$ & $05 / 02 / 2000^{\mathrm{a}}$ & $31 / 01 / 2010^{b}$ & $29 / 01 / 2020^{c}$ & USGS \\
\hline Adama & $168 / 054$ & $04 / 02 / 1990^{a}$ & $05 / 02 / 2000^{\mathrm{a}}$ & $31 / 01 / 2010^{b}$ & $29 / 01 / 2020^{c}$ & USGS \\
\hline Bahir Dar & $170 / 052$ & $02 / 02 / 1990^{a}$ & $11 / 02 / 2000^{\mathrm{a}}$ & $14 / 02 / 2010^{b}$ & $18 / 02 / 2020^{c}$ & USGS \\
\hline Hawassa & $168 / 055$ & $19 / 01 / 1990^{a}$ & $12 / 01 / 2000^{\mathrm{a}}$ & $31 / 01 / 2010^{b}$ & $19 / 01 / 2020^{c}$ & USGS \\
\hline
\end{tabular}

\footnotetext{
a Landsat TM: ${ }^{\mathrm{b}}$ Landsat ETM +: ' Landsat OLS
} 
Table 2 Types of LULC and its description

\begin{tabular}{|c|c|}
\hline LULC type & Description \\
\hline Urban forest and greenery & $\begin{array}{l}\text { Areas occupied by plantation forest and urban green parks with } 65 \% \text { canopy cover or higher, evergreen and mixed urban } \\
\text { forests and greenery and other vegetation that is relatively tall and dense, as well as areas covered with both indigenous } \\
\text { and exotic tree }\end{array}$ \\
\hline Urban agriculture & $\begin{array}{l}\text { The purpose of which is used for urban crop production and livestock husbandry grazing land by peri-urban field farmers, } \\
\text { although cultivated land use is relatively different in terms of size, soil fertility, use of input, and other important variables } \\
\text { from rural agriculture. Includes, grazing areas, cultivated lands, community open lands and areas along the lake shore } \\
\text { that are used for agricultural purposes when the lake level retreats following the long dry-season }\end{array}$ \\
\hline Water bodies & $\begin{array}{l}\text { Permanent natural water bodies such as lakes, rivers, ponds reservoirs, and man-made water bodies, the water table in } \\
\text { irrigated land }\end{array}$ \\
\hline Built up & $\begin{array}{l}\text { The built-up area with congested buildings includes all types of artificial surfaces, residential and scattered settlements in } \\
\text { urban fringe zones, commercial, industrial land uses as well as transportation infrastructure }\end{array}$ \\
\hline Bare land & $\begin{array}{l}\text { The land consists of roads, rocky outcrops, and degraded lands, where the area is dominated by the regular movement of } \\
\text { trucks, quarry for road construction, and abandoned lands as a result of gully formation etc }\end{array}$ \\
\hline
\end{tabular}

Source: (Gashu and Gebre-Egziabher 2018)

\section{Satellite data acquisition and preparation}

In this study, three decades' time-series LULC change maps for each city were prepared by utilized multispectral Landsat imagery (Landsat $7 \mathrm{TM}, \mathrm{ETM}^{+}$, and Landsat 8 OLI), which were retrieved on four distinct dates: 1990, 2000, 2010, and 2020 free of charge from the United States Geological Survey (USGS) website (https://earth explorer.usgs.gov). All images were retrieved more or less during the same period during the dry seasons of the particular years (Table 1). Since most land-surface features show reliable reflectance characteristics regardless of the year of acquisition. Moreover, the retrieved images were exported to ArcGIS and re-projected in the WGS 84 system of the Universal Transverse Mercator (UTM) projection fuse of $37 \mathrm{~N}$.

The pre-processing of satellite images was accomplished using color composites in RGB transformation. To categorize LULC classes, a false-color grid composite image was generated using ERDAS virtual Geographical Information System (GIS) analyzer. Primary, to get the major ecosystem types of each city an unsupervised classification technique was made, which then used for supervised classification. Spectral signatures and ground verification using Geographical Positioning System (GPS) were used to verify the accuracy of the LULC map of 2020 with field points. About 1000 (50 for each LULC type per city) random ground truth points and highresolution images of Google earth points were acquired for confirmation of LULC classification results. Later, the ecosystem type classification was done using the maximum likelihood classifier (Yang et al. 1999; Feyisa et al. 2016; Feyissa and Gebremariam 2018; Minta et al. 2018; Hoque et al. 2020).

Finally, the LULC map with five distinguished ecosystem classes of respective reference years $(1990,2000$, 2010, and 2020) and temporal changes in LULC change per city was generated and analyzed for interpretation. The five classes were: urban forest and greenery, urban agriculture, urban built, bare land, and water (Table 2). These five-LULC classification systems were chosen considering the standard classes explained by the National Aeronautics and Space Administration (NASA) and the US Geological Survey (USGS) as well as the study detail and objectives (Mohan et al. 2011; Gashu and GebreEgziabher 2018).

\section{Data analysis}

This study uses the post-classification changes detection method. Due to its nature of clearly identified change, trends, and rate of ecosystem dynamics (Lu et al. 2004; Gashu and Gebre-Egziabher 2018). The post-classification was executed by recoding, majority filtering, clumping, elimination, and mosaicking of the classified maps to reduce errors of all LULC maps using the ArcMap GIS. Zonal statistics in ArcGIS Spatial Analyst's tool was applied to assess the LULC dynamics of each city by using cross tabulating pairs of time intervals i.e., 19902000, 2000-2010, and 2010-2020. Moreover, quantified values of the changes between the different LULC classes were used for statistical analysis to reveal the extent of the dynamics in the study areas. The percentage of change within the same LULC class between twotime points is computed using Eq. 1 and interpreted if the values are positive suggest again, whereas negative values imply a loss in extent. Moreover, the LULC change rate was also detected using formula 2 .

$$
\begin{aligned}
& \text { Change }(\%)=\frac{\left(A_{t n}-A_{t n-1}\right) * 100}{A_{t n-1}} \\
& r=\frac{1}{\Delta t \ln \left(A_{2}-A_{1}\right)}
\end{aligned}
$$


where: $A_{t n}$ area of specific land use land cover class at time $t_{n} ; A_{t n-1}$-an area of the same land use land cover class at time $t_{n}-{ }_{1}$; Change (\%)-percent change in the area of specific land use land cover class between times $t_{n}$ and $t_{n-1 ;} r$ is the annual rate of change in $\%, \Delta t$ is the time interval in years during the LULCC being assessed; $\ln$ is the base of the natural logarithm function.

Besides, to reveal the spatial relations between LULC change and response for anthropogenic-sustainability nexus, we first compute LULC dynamics rate for a specific and integrated land use land cover transformation of each city from 1990 to 2020 period, using three effective integrated parameters: land use dynamic degree (single land use dynamic degree (SLUDD), integrated land use dynamic degree (ILUDD), land-use intensity (LUI) and land-use diversity (LUD) methods (Zorrilla-Miras et al. 2014; Song and Deng 2017; Chen et al. 2019; Hu et al. 2019; Huang et al. 2019; Liu et al. 2020b; Shao et al. 2020) followed Eqs. 3-6.

Single land use dynamic degree (SLUDD) reveals the change rate of a single land-use type of each city, while Integrated Land Use Dynamic Degree (ILUDD) estimates the overall situation of land-use change rate (Chu et al. 2018; Chen et al. 2021). Besides, Land use intensity (LUI) is revealing the breadth and depth of land use, which can be determined as a reply to the material and energy flows between natural and human ecosystems and can be used to evaluate the intensity of the adaptations of a land-use system to the changing physical and socio-economic circumstances (Zorrilla-Miras et al. 2014; Chen et al. 2020). According to Chen et al. (2019) the intensity of interaction divided into four ('open space/bare land, was assigned the weighted value of 1 , whereas urban built land was given the weighted value 4. Urban Forest and greenery land and water areas, were given the weighted value 2, while urban agriculture land was assigned the weighted value of 3) based on the equilibrium states of physical and socioeconomic influences on the land-use systems. Furthermore, land-use diversity (LUD) represents LULC dynamics about the structure, richness, and complexity of different land-use types.

$$
\begin{aligned}
& \text { SLUDD }=\frac{\mathrm{LA}_{\mathrm{I}, \mathrm{t} 2}-\mathrm{LA}_{\mathrm{I}, \mathrm{t} 1}}{\mathrm{LA}_{\mathrm{I}, \mathrm{t} 1}} * \frac{1}{\mathrm{~T}} * 100 \% \\
& \mathrm{ILUDD}=\left(\sum_{\mathrm{i}=1}^{\mathrm{n}} \Delta \mathrm{LA}_{\mathrm{i}-\mathrm{j}} \mid \sum_{\mathrm{i}=1}^{\mathrm{n}} \mathrm{LA}_{(\mathrm{I}, \mathrm{t} \mathrm{t})}\right) * \frac{1}{\mathrm{~T}} * 100 \% \\
& \mathrm{LUI}=\sum_{\mathrm{i}=1}^{4} \frac{\mathrm{LA}_{(\mathrm{I}, \mathrm{t})}}{\sum_{\mathrm{i}=1}^{\mathrm{n}} \mathrm{LA}_{(\mathrm{I}, \mathrm{t})}} * \mathrm{D}_{\mathrm{I}}
\end{aligned}
$$

$$
\mathrm{LUD}=-\sum_{\mathrm{i}=1}^{\mathrm{n}} \frac{\mathrm{LA}_{(\mathrm{I}, \mathrm{t})}}{\sum_{\mathrm{i}=1}^{\mathrm{n}} \mathrm{LA}_{(\mathrm{I}, \mathrm{t})}} * \ln \left(\frac{\mathrm{LA}_{(\mathrm{I}, \mathrm{t})}}{\sum_{\mathrm{i}=1}^{\mathrm{n}} \mathrm{LA}_{(\mathrm{I}, \mathrm{t})}}\right)
$$

where $\mathrm{LA}_{(\mathrm{I}, \mathrm{t} 1)}$ and $\mathrm{LA}_{(\mathrm{I}, \mathrm{t} 2)}$ characterize the area of land use type I at time $t_{1}$ and $t_{2}$, respectively. $\Delta \mathrm{LA}_{\mathrm{i}-\mathrm{j}}$ is the area of land use type I transformed to land use type $j(j=1,2, n$, $I \neq j$ ) during the study period, $n$ is the number of land-use types in the study area, $T$ is the study period, and $D_{i}$ is the weighted value of each land-use type mentioned previously (Fig. 3).

Furthermore, to measure annual urban expansion, we chose and calculated two indexes-Annual Increase (AI) and Annual Growth Rate (AGR) of urban land (Wu 2013; Meng et al. 2020; Zhao and Fan 2020). Annual increase (AI) is efficient to compare the expansion rates for the same city among different periods, while annual growth rate (AGR) is more suitable for comparison among different cities (Alawamy et al. 2020; Meng et al. 2020). Indexes used to quantify the urban growth rates are defined using Eqs. 7 and 8.

$$
\begin{aligned}
& A L=\frac{A_{\text {end }}-A_{\text {start }}}{d} \\
& A G R=100 \% *\left[\left(\frac{A_{\text {end }}}{A_{\text {start }}}\right)^{\frac{1}{d}}-1\right]
\end{aligned}
$$

where $\mathrm{A}_{\text {start }}$ and $\mathrm{A}_{\text {end }}$ are the areas of urban land at the initial and end time, respectively, and $d$ (in years) is defined as the period of the study period (Fig. 2).

The classification accuracy assessments of the resulting LULC types of satellite images were carried out by comparing the sample LULC class of the classified layer and the reference layer (Gashaw et al. 2018; Gashu and Gebre-Egziabher 2018). Since image classification without accuracy assessment mostly affects the confidence of the findings (Yang et al. 1999). The overall accuracy and Kappa scrutiny were calculated to appraise the degree of classification accuracy of the error matrix (Story et al. 1986; Yang et al. 1999). Overall accuracy is the ratio of a total number of randomly generated reference values of the error matrix to the sum of correctly classified values (Minta et al. 2018; Yu et al. 2019). While, the Kappa coefficient, is a statistical measure of inter-rater reliability (actual and chance agreement) that is compared to reference data. The formula for computing producer accuracy, user accuracy, overall accuracy, and Kappa index coefficient was computed using Eqs. 9-12.

The overall accuracies of $88.75 \%$ (Addis abba), $89.13 \%$ (Adama), 86.63\% (Hawassa), and 86.68\% (Bahir Dar) were achieved (Table 3). The kappa index results showed that 


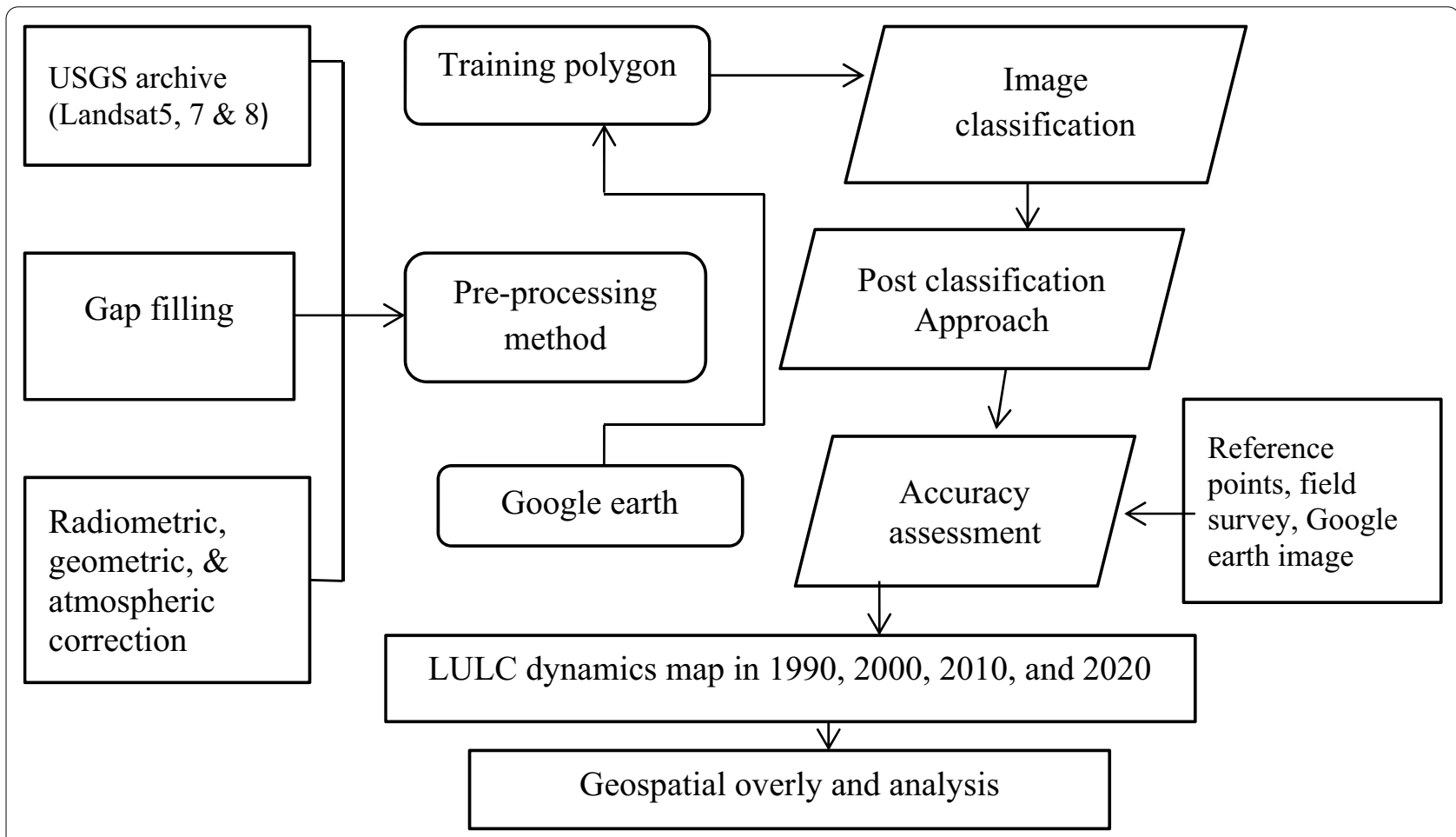

Fig. 2 Flow chart of methodological approach

Table 3 Accuracy assessment for classified images of Addis Ababa, Adama, Bahir Dar and Hawassa

\begin{tabular}{|c|c|c|c|c|c|c|c|}
\hline Reference year & Classified image & $\begin{array}{l}\text { Overall } \\
\text { classification } \\
\text { accuracy (\%) }\end{array}$ & $\begin{array}{l}\text { Overall } \\
\text { kappa } \\
\text { coefficient }\end{array}$ & Reference year & Classified image & $\begin{array}{l}\text { Overall } \\
\text { classification } \\
\text { accuracy (\%) }\end{array}$ & $\begin{array}{l}\text { Overall } \\
\text { kappa } \\
\text { coefficient }\end{array}$ \\
\hline Addis Ababa & & & & Adama & & & \\
\hline 1990 & Landsat $5 \mathrm{TM}^{\mathrm{a}}$ & $89.50 \%$ & 0.86 & 1990 & Landsat 5 TM & $86.50 \%$ & 0.83 \\
\hline 2000 & Landsat 5 TM & $90.00 \%$ & 0.87 & 2000 & Landsat 5 TM & $88.50 \%$ & 0.86 \\
\hline 2010 & Landsat 7 ETM $+{ }^{b}$ & $88.00 \%$ & 0.84 & 2010 & Landsat 7 ETM+ & $90.00 \%$ & 0.88 \\
\hline 2020 & Landsat 8 OLK & $87.50 \%$ & 0.82 & 2020 & Landsat 8 OLI & $91.50 \%$ & 0.89 \\
\hline Bahir Dar & & & & Hawassa & & & \\
\hline 1990 & Landsat 5 TM & $85.00 \%$ & 0.82 & 1990 & Landsat 5 TM & $89.00 \%$ & 0.86 \\
\hline 2000 & Landsat 5 TM & $86.50 \%$ & 0.84 & 2000 & Landsat 5 TM & $85.00 \%$ & 0.81 \\
\hline 2010 & Landsat 7 ETM+ & $88.00 \%$ & 0.87 & 2010 & Landsat 7 ETM+ & $85.50 \%$ & 0.82 \\
\hline 2020 & Landsat 8 OLI & $87.00 \%$ & 0.85 & 2020 & Landsat 8 OLI & $88.00 \%$ & 0.86 \\
\hline
\end{tabular}

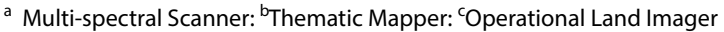

all of the images met the minimum of $85 \%$ accuracy in LULC change analysis to each classified ecosystem that intersects a given reference ecosystem. This result is aligning with the recommended value of many scholars (Lu et al. 2004; Li et al. 2019; Ha et al. 2020).

$$
\text { Producer's accuracy } \mathrm{i}=\frac{\text { nii }}{\text { Gii }}
$$

$$
\begin{aligned}
& \text { User's accuracy } \mathrm{i}=\frac{\text { nii }}{\mathrm{Cii}} \\
& \text { Overall accuracy }=\frac{\sum_{i=1}^{k} n i i}{n} \\
& \text { Kappa coefficient } K=\frac{N \sum_{i=1}^{r k} x a b-\sum_{i=1}^{r}(x a * b)}{N^{2}-\sum_{i=1}^{k}(x a+* x b)}
\end{aligned}
$$


where: $i$ is the class number, $n$ is the total number of classified pixels that are being compared to ground truth, nii is the number of pixels belonging to the ground truth class $i$, that have also been classified with class $\mathrm{i}, \mathrm{Ci}$ is the total number of classified pixels belonging to class $i$ and $\mathrm{Gi}$ is the total number of ground truth pixels belonging to class $\mathrm{I}$, Khat = Kappa coefficient; $\mathrm{N}$ is a total number of values; $\sum \mathrm{i}=1^{\mathrm{K}} \mathrm{Xab}$ is observed accuracy, and $\sum \mathrm{i}=1 \mathrm{~K}$ $\left(\mathrm{X}_{\mathrm{a}} \times \mathrm{X}_{\mathrm{b}}\right)$ is change accuracy.

\section{Results}

\section{Land use land cover dynamics}

The Spatio-temporal land-use dynamics degree of each city with the corresponding percentage is illustrated in Tables 4, 5, 6, 7 and Fig. 3. This study showed that a substantial amount of ecological land was converted to build-up from 1990 to 2020, which was characterized by a net upsurge in building up and a large reduction of the urban forest, urban agriculture, and bare land ecosystem (Figs. 4 and 5). In general, from 1990 to 2020 the total built-up ecosystem was boosted by $17,341.0$ ha (32.16\%), 2151.27 ha (19.64\%), 2715.21 ha (12.21\%), and 2599.65 ha (15.71\%) for Addis Ababa, Adama, Bahir Dar, and Hawassa cities respectively. Whereas, the urban agricultural ecosystems were reduced by $13.63 \%, 19.1 \%, 22.9 \%$, and $9.33 \%$ for Addis Ababa, Adama, Bahir Dar, and Hawassa cities respectively and a significant portion was transformed to build up the ecosystem and its dynamic degree was $20.79 \%$ (Table 4).

Besides, urban forest and greenery ecosystems of Adma and Bahir Dar cities were grown by 443.11 ha (4.09\%) and 2121.3 ha $(9.94 \%)$ respectively that of 1990 . On the other hand, the size of urban forest and greenery ecosystems of Addis Ababa and Hawassa cities were reduced by 1496.94 ha $(2.77 \%)$ and 507.96 ha $(3.07 \%)$ in that orders from the initial period (Tables 4 and 5). Furthermore, the annual conversion rate of bare land to build up was $16.1 \%, 4.56 \%, 0.82 \%$, and $2.17 \%$ per year for Addis Ababa, Adama, Bahir Dar, and Hawassa cities respectively from the 1990 to 2020 period.

Specifically, in 1990 urban agricultural ecosystem was accounted for more than half of the total area of Hawassa (56.30\%) and Adama (53.90\%) followed by Bahir Dar (40\%), and Addis Ababa (39.00\%). Moreover, the highest urban forest and greenery portion was found in Bahir Dar (43.90\%), followed by Hawassa (20.10\%), Adama (16.40\%), and Addis Ababa (13\%) cities (Fig. 4). On the other hand, the built-up area was accounted for in Addis Ababa (23.40\%), Adama (15.70\%), Hawassa (9.80\%) and, Bahir Dar (6.50\%) ascending order. In 2000, the urban agriculture ecosystem was increased in Addis Ababa by $10 \%$, followed by Adama by $2 \%$, whereas, it was declined by $20 \%$ and $2 \%$ from Bahir Dar and Hawassa cities respectively from 1990 coverage. In the case of the urban built-up, the highest agglomeration was found in Addis Ababa and Adama cities by $4 \%$, followed by Hawassa and Bahir Dar by $2 \%$ for the initial year. In contrast, the urban forest and greenery cover was significantly increased in Bahir Dar by 13\% (2206.7 ha). Conversely, the cover was declined in other cities. Vis-à-vis the size of bare land was increased in Bahir Dar and Hawassa cities, while the conversion to other types of the ecosystem was rapid in Addis Ababa and Adama cities (Table 4).

In 2010, the ecosystem under urban agriculture was covered by 44,698.66 ha of the total cityscapes, afterward, the built-up area and urban forest and greenery accounted for 25, 652.17 ha, 13,819.05 ha respectively, while the coverage of water body was declined to 2645.28 ha (Table 3). Moreover, Addis Ababa, Hawassa, and Bahir Dar cities were shown the declining trend of the urban agricultural ecosystem, while the coverage of the urban agriculture in Adam had shown increment with the cost of bare land utilization. Regarding, the built-up ecosystem, the largest agglomeration was found in Addis Ababa and increased by $14.60 \%$ from 1990, consequently other cities sprawl by $4 \%$ from 1990 . In contrast, bare land (open space) and urban forest ecosystems were reduced dramatically and replaced by built up an ecosystem (Table 5).

In 2020, the built-up ecosystem accounted for a significant proportion in all cities, which accounts for more than double that of 1990. The built-up ecosystem was augmented by $32.16 \%$ in Addis Ababa city, $19.64 \%$ in Adama, Bahir Dar (12.72\%), and by $15.72 \%$ in Hawassa (Table 4). Besides, the urban agriculture ecosystem was decreased by 8694.26 ha, 499.41 ha, 177.93 ha, and 358.74 ha from Addis Ababa, Adama, Bahir Dar, and Hawassa cities in that order (Table 4). Similarly, the urban forest and greenery ecosystem of Addis Ababa and Hawassa cities were declined from 1490.94 ha $(2.77 \%)$ and 507.96 ha (3.07\%) respectively. However, an increment was observed in Adama and Bahir Dar cities by 448.11 ha and 2121.3 ha in the past three decades. Besides, the size of water bodies was declined in Adama, Bahir Dar, and Hawassa cities by 13.27 ha, 108.09 ha, and 189.27 ha in that order.

Furthermore, Table 5 shows the persistence, gains, losses and net changes of different LULC change accordingly, in Hawassa city, built up has shown a higher persistence value and accounted for $55.56 \%$ followed by urban agriculture ecosystem (30.54\%) while bare land (open space) has shown a higher loss (55\%). Besides, the ecosystem type which persisted the least is urban forest and greenery $(4.8 \%)$ and the ecosystem with the least loss is water body (0.1\%). In Bahir Dar, the urban ecosystem 


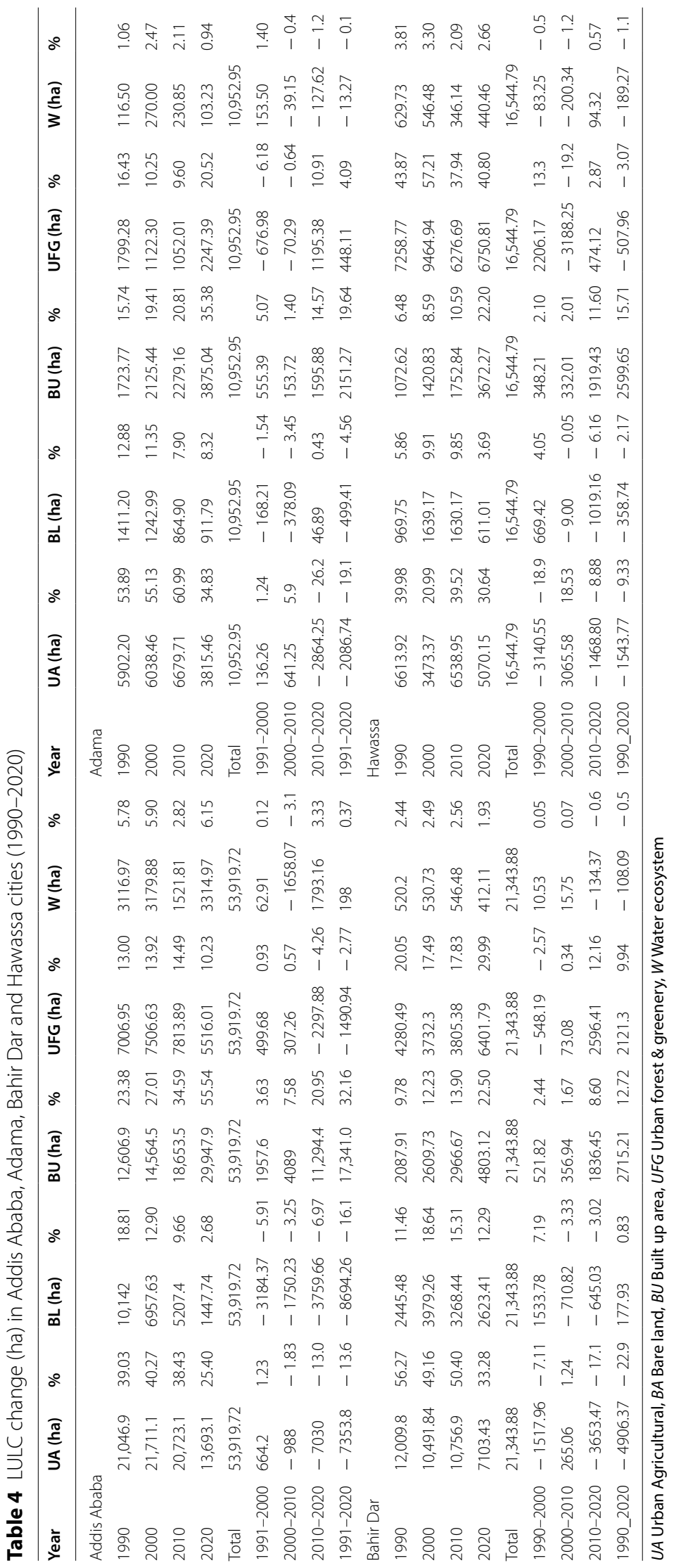




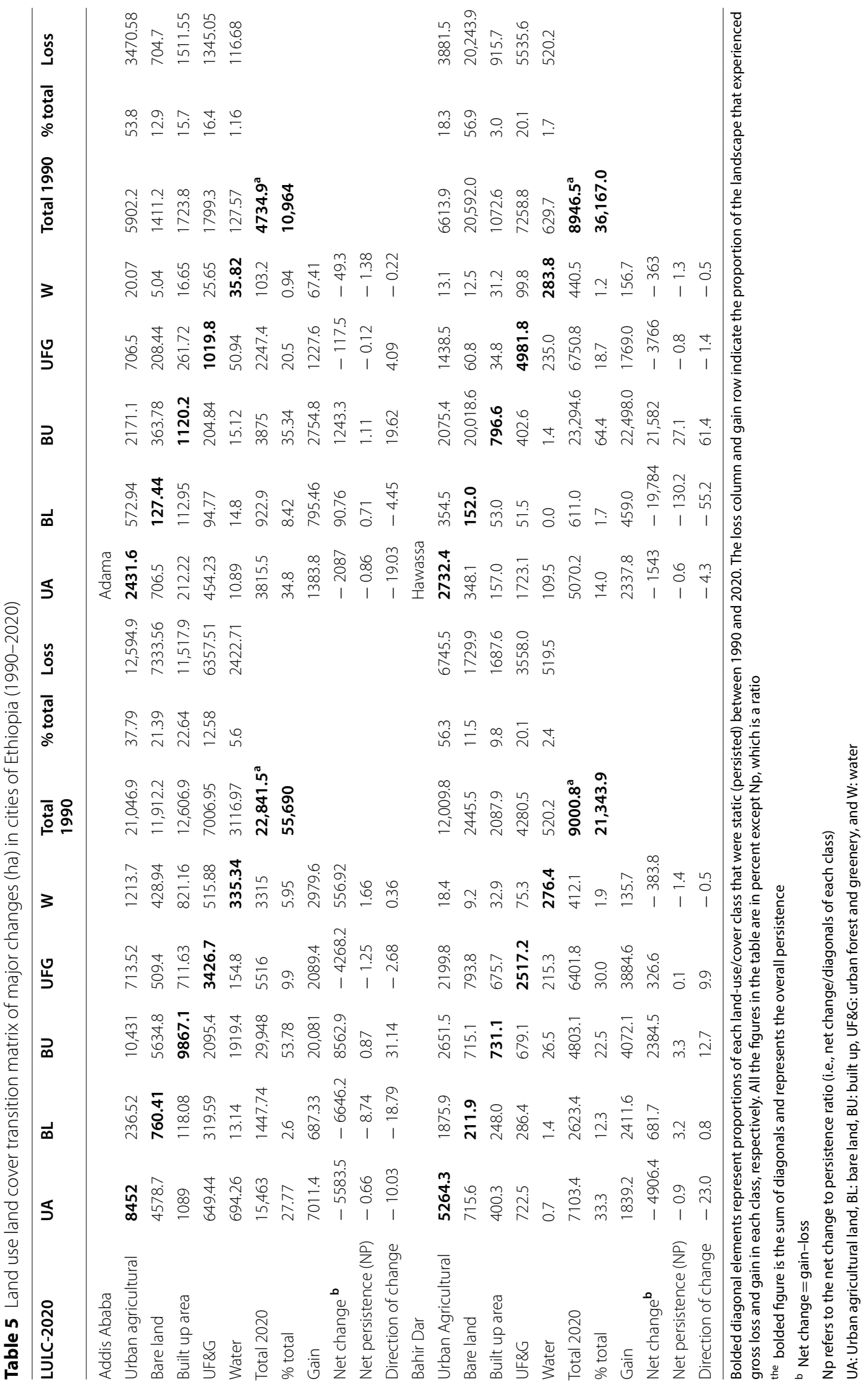


Table 6 Annual Increase (AI) and Annual Growth Rate (AGR) of each city

\begin{tabular}{lllll}
\hline Al (ha) & $\mathbf{1 9 9 0 - 2 0 0 0}$ & $\mathbf{2 0 0 0 - 2 0 1 0}$ & $\mathbf{2 0 1 0 - 2 0 0 0}$ & Average \\
\hline Addis Ababa & 195.76 & 408.90 & 1129.44 & 578.03 \\
Hawassa & 52.18 & 35.69 & 183.65 & 90.51 \\
Adama & 40.17 & 15.37 & 159.59 & 71.71 \\
Bahir Dar & 34.82 & 33.20 & 191.94 & 86.66 \\
AGR (\%) & $1990-2000$ & $2000-2010$ & $2010-2000$ & Average \\
Addis Ababa & 27.68 & 41.54 & 77.43 & 46.89 \\
Hawassa & 38.14 & 25.63 & 78.93 & 47.57 \\
Adama & 36.27 & 18.51 & 87.90 & 47.56 \\
Bahir Dar & 46.39 & 36.34 & 131.54 & 71.42 \\
\hline
\end{tabular}

with the highest persistence in urban agriculture, ecosystem $(60 \%)$ and that with the highest loss is urban forest and greenery (70\%). Whereas built-up ecosystem has shown low persistence and losses, but a higher gain percentage. Overall, the results show that $53 \%$ of Bahir Dar and $48 \%$ of Hawassa urban ecosystems remained unchanged over the 1990-2020 periods. On the other hand, $47 \%$ of Bahir Dar and 52\% of Hawassa LULC changed during 1990-2020. This indicates that there is a higher rate of LULC dynamics in Hawassa city than in Bahir Dar city in the last four decades (Tables 4 and 5: Fig. 3).

In Addis Ababa, bare land experienced the least persistent, whereas urban built-up was the most persistent ecosystem type (Table 5). The net change in persistence ratio was large for bare land (negative), urban agriculture land (negative), urban forest, and greenery (negative), and built-up land (positive). Overall, 22,841.5 ha of the total ecosystem remains unaffected (Table 5). Moreover, the mass land of the dynamics was shown from urban agriculture to build up, as compared to other land uses. Besides, in Adama, water bodies experienced the least persistent, whereas urban built-up and bare land was the most persistent ecosystem type (Table 5). The net change in persistence ratio was large for water body (negative), urban agriculture land (negative), urban forest and greenery (positive), and built-up land (positive). Overall, 9000.8 ha of the total landscape remains unaffected (Table 5).

\section{Spatial patterns of land use land cover change}

The spatial distribution LULC dynamics have been scrutinized in four phases, such as 1990-2000, 2000-2010, 2010-2010, and 1990-2020 to explore the changes that took place among the ecosystems (Figs. 3 and 4). Spatial patterns of ecosystem types in the cityscapes level had shown "urban agriculture $>$ urban forest and greenery $>$ bare land / open space $>$ built up" from urban agricultural and/or forest ecosystem to multi-complex human-made built up an ecosystem (Figs. 3 and 4). Generally, Bahir Dar and Adama cities were manifested by a mono-nuclei agglomerating from their urban center, and two secondary nuclei rapidly stretched out after 2010, forming a tri-core urbanization pattern (Fig. 4a, d). Addis Ababa and Hawassa cities have shown a multicore urban agglomeration and new development was sprinkled

Table 7 Land use dynamic degree (SLUDD and ILUDD) in cities from 1900 - 2020 (\%)

\begin{tabular}{|c|c|c|c|c|c|c|c|c|}
\hline \multirow{2}{*}{$\begin{array}{l}\text { Cities } \\
\text { LULC type/year }\end{array}$} & \multicolumn{4}{|c|}{ Addis Ababa city } & \multicolumn{4}{|c|}{ Bahir Dar city } \\
\hline & 1990-2000 & $2000-2010$ & $2010-2020$ & $1990-2020$ & $1990-2000$ & $2000-2010$ & $2010-2020$ & $1990-2020$ \\
\hline Urban agricultural & 0.32 & -0.46 & -3.39 & -1.20 & -1.26 & 0.25 & -3.40 & -1.36 \\
\hline Bare land & -3.14 & -2.52 & -7.22 & -2.96 & 6.27 & -1.79 & -1.97 & 0.24 \\
\hline Built up area & 1.55 & 2.81 & 6.05 & 7.48 & 2.50 & 1.37 & 6.19 & 4.33 \\
\hline Urban forest \& greenery & 0.71 & 0.41 & -2.94 & -0.73 & -1.28 & 0.20 & 6.82 & 1.65 \\
\hline Water & 0.20 & -5.21 & 11.78 & -0.89 & 0.20 & 0.30 & -2.46 & -0.69 \\
\hline ILUDD & -0.36 & -4.97 & 3.07 & 1.70 & 6.43 & 0.33 & 5.18 & 4.17 \\
\hline Cities & \multicolumn{4}{|l|}{ Adama city } & \multicolumn{4}{|c|}{ Hawassa city } \\
\hline LULC type/year & 1990-2000 & 2000-2010 & 2010-2020 & $1990-2020$ & $1990-2000$ & 2000-2010 & 2010-2020 & 1990-2020 \\
\hline Urban agricultural & 0.23 & 1.06 & -4.29 & -1.18 & -4.75 & 8.83 & -2.25 & -0.78 \\
\hline Bare land & -1.19 & -3.04 & 0.54 & -1.18 & 6.90 & -0.05 & -6.25 & -1.23 \\
\hline Built up area & 2.33 & 0.72 & 7.00 & 4.16 & 3.25 & 2.34 & 10.95 & 8.08 \\
\hline Urban forest \& greenery & -3.76 & -0.63 & 11.36 & 0.83 & 3.04 & -3.37 & 0.76 & -0.23 \\
\hline Water & 13.18 & -1.45 & -5.53 & -0.38 & -1.32 & -3.67 & 2.72 & -1.00 \\
\hline ILUDD & 10.78 & -3.33 & 9.09 & 2.25 & 7.12 & 4.07 & 5.93 & 4.83 \\
\hline
\end{tabular}



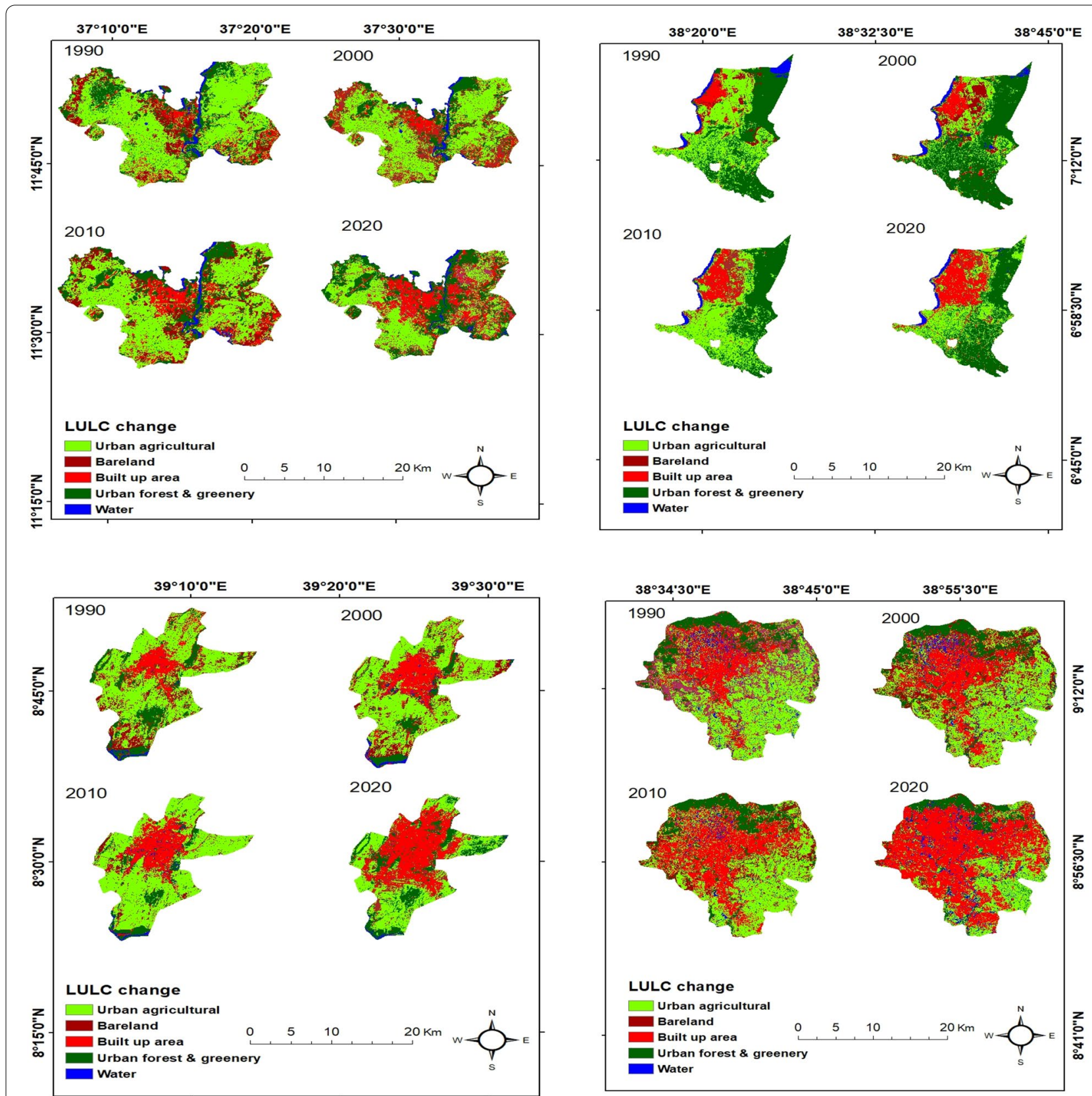

Fig. 3 Spatial distribution of LULC in (a) 1990, (b) 2000, (c) 2010 and (d) 2020 Bahir Dar, Hawassa, Adama and Addis Ababa cities respectively

across all directions from the initial period of urbanization in 2020 (Fig. 4b, c). Particularly, the built-up ecosystem growth of Addis Ababa concerted mainly in the northwest, which was the initial economic zone of the city, and then stretched to the southwest parts of the city over 2010, due to the new house development program by the city government.
Extent and rates of urban agglomeration

During the 1990s, urban agricultural land, and urban forest and greenery were predominant ecosystem types in all cities. Built-up and water bodies accounted for the comparatively small ecosystem (Table 6 and Fig. 5). However, in 2020 the ecosystems were substantially declined concurrent with the significant increases in urbanization throughout the cities. The Annual Increase (AI) of urbanization of Addis Ababa 

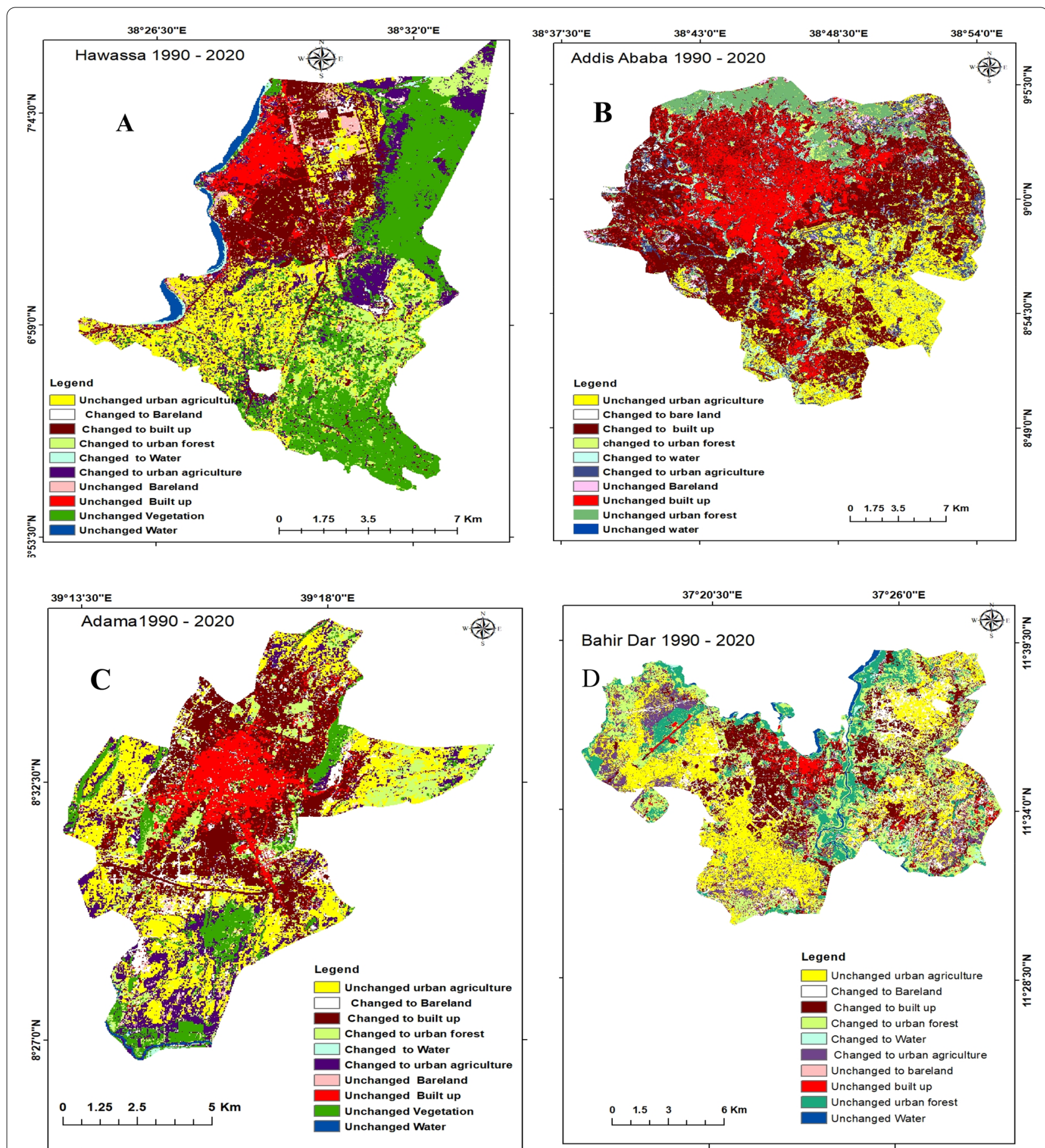

Fig. 4 Spatial patterns and LULC change transition of cities from 1990 to 2020

city constantly augments from 1990 to 2020 while, cities like Hawassa, Adama, and, Bahir Dar were declined substantially to 35.69 ha, 15.37 ha, and 33.20 ha in the second period of 2000-2010 respectively and exponentially augmented between 2010 and 2020. Moreover, after removing the effect of city size, the annual spreading out rate (AGR) of Addis Ababa city has become $48.89 \%$, and the Bahir Dar city was substantially increased by $71.42 \%$. For all cities, the AGR was the highest during the 2010-2020 period of the past three decades. During 2000-2010, Hawassa, Adama and, Bahir Dar cities reached their lowest expansion 


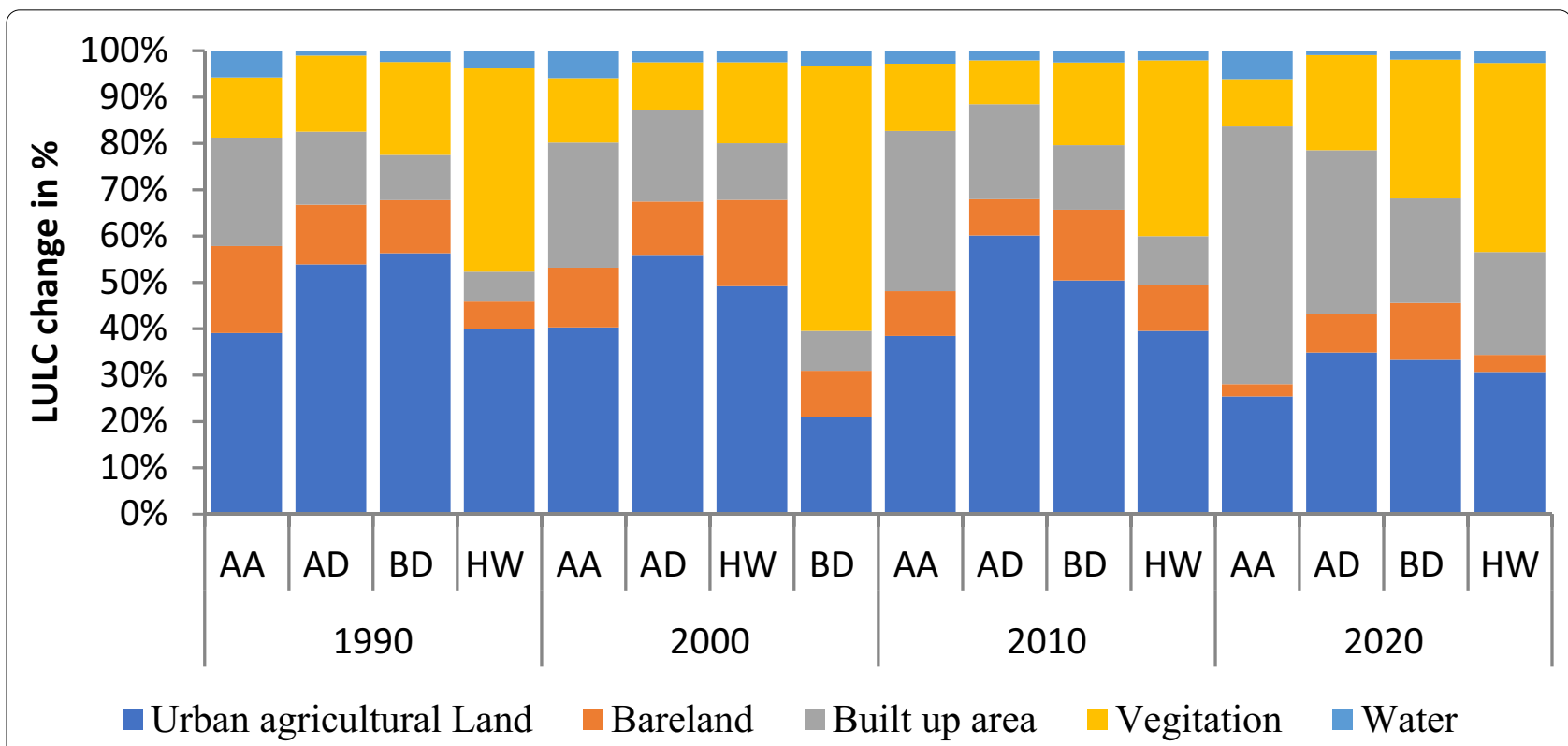

Fig. 5 Size and percentage contribution of each of five ecosystem types in each city and the total study area

rate over the past three decades, while the AGR of Bahir Dar was double the AGR of other cities in 20102020 (Table 6). This shows that the dynamics degree of the none built-up area upsurge in built-up land in the last 10 years has accelerated, as the result of new housing construction strategies of the country and illegal shifting bare land and urban agriculture to build up.

\section{Temporal and spatial analysis of SLUDD, ILUDD, LUI, and LUD}

Single land use dynamic degree (SLUDD) result shows that a substantial variation between the cities in the past three decades. The highest SLUDD was identified for building up ecosystem type in Bahir Dar city (8.08\%) followed by Addis Ababa, Adama, and Hawassa cities respectively (Fig. 6). On the other hand, urban agriculture declined by $22.99 \%$ in Bahir Dar city, followed by Adama and Addis Ababa cities by $19.05 \%$ and $13.64 \%$ respectively. The SLUDD of bare land (open space) was decreased annually by $16.20 \%, 4.56 \%$, and $3.07 \%$ in Addis Ababa, Adama, and Hawass cities, and most of the portions were converted to build up an ecosystem. However, the SLUDD value of urban forests and greenery was augmented in Adama and Hawassa cities by $1.65 \%$ and $0.83 \%$ (Fig. 6).

Conversely, from 1990 to 2020, the ILUDD in Addis Ababa, Bahir Dar, Adama, and Hawassa cities were 1.7\%, $4.17 \%, 2.25 \%$, and, $4.83 \%$ respectively (Table 7 ). Moreover, the ILUDD was highest in the first period (1990 to 2000) of the study in Bahir Dar, Adama, and Hawassa cities. This indicated that cities experienced rapid land-use dynamics during this period, with the ILUDD at $6.43 \%$, $10.78 \%$, and $7.12 \%$. While it was negative in Addis Ababa city $(0.36 \%)$. After 2000 , the ILUDD negatively declined, and it was the lowest from 2000 to 2010 at 4.97\%, 3.3\%, and 3.33\% degree in Addis Ababa, Bahir Dar, Adama cities. Besides, comparing the dynamics degree in different LULC types, the conversion rate of the built-up ecosystem, water bodies, and urban forest and greenery were significantly high, whereas the urban agricultural ecosystem and, bare land exhibited a reduced trend.

The SLUDD of built up of all cities has shown a linear continuously increasing trend from 1990 to 2020 (7.48\%, 4.33\%, 4.16\%, and 8.08\% in Addis Ababa, Bahir Dar, Adama, and Hawassa, respectively), while a continuous negative reduction was found in the dynamic in farmland $1.20 \%, 1.36 \%, 1.18 \%$, and $0.78 \%$ in Addis Ababa, Bahir Dar, Adama, and Hawassa, in that order). The spatial transformation in land use dynamics was meticulously associated with urbanization. Between 1990 and 2020, the ILUDD of Hawassa city in the central part was considerably higher than in other parts of the city and expand to northeastern and southeastern parts of the city (Fig. 7).

The overall dynamics LUIs of each city in the years 1990-2020 were 3.31, 4.82, 5.04, and 3.56, for Addis Ababa, Hawassa, Adama, and Bahir Dar cities respectively. In all cities, LUIs growing tendency was found from 1990 to 2000 at a growth rate of 4\%. However, the magnitude of the growth rate of LUI was slightly increased with the rate of $15 \%$ in the period of 2000 to 2010 and $23 \%$ in the period of 2010 to 2020 , and $42 \%$, and 


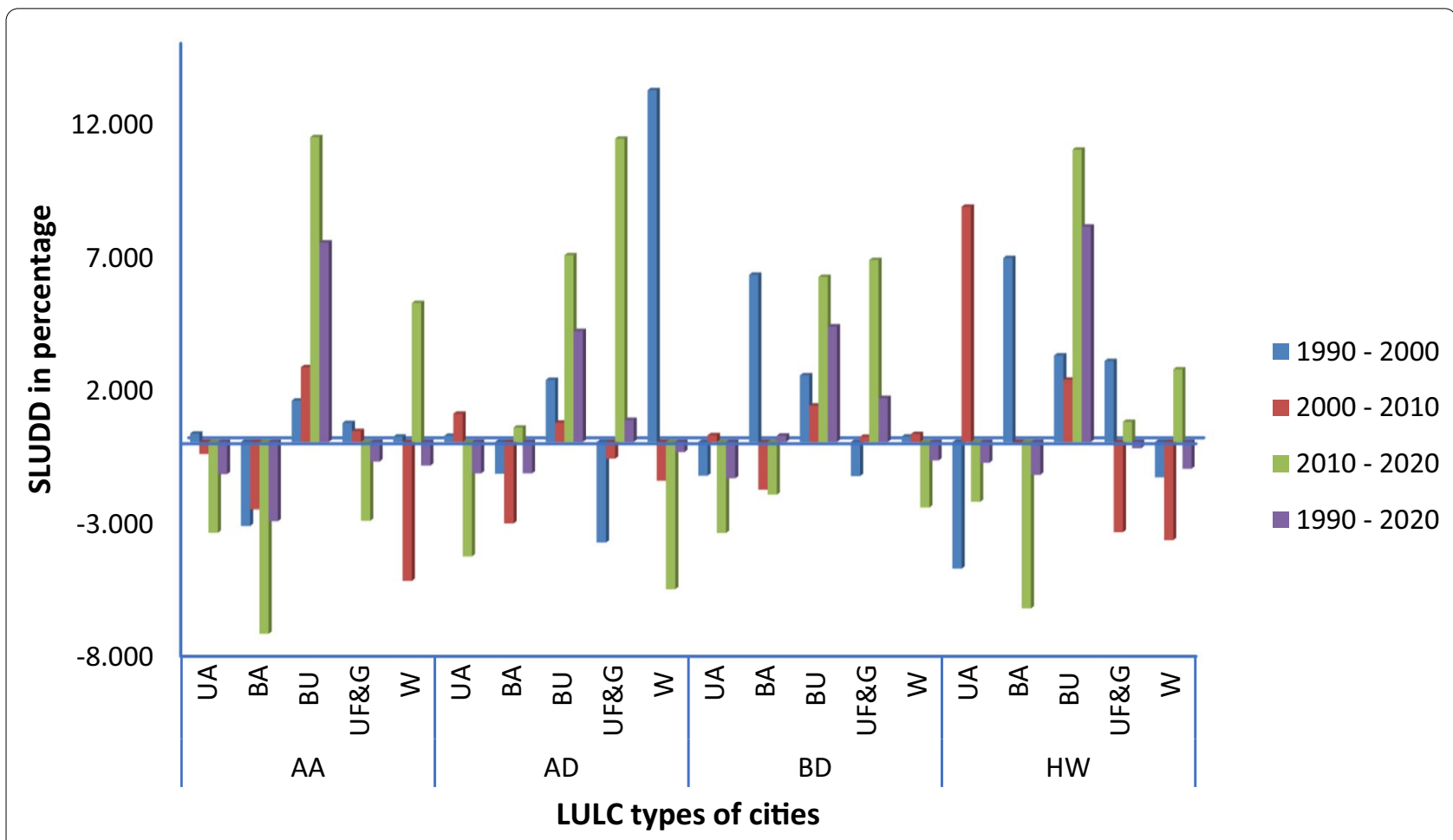

Fig. 6 The percentage of the SLUDD of LULC in cities. *AA: Addis Ababa, AD: Adama, BD: Bahir Dar and HW: Hawassa, UA: Urban agriculture, BL: bare land, BU: built up, W: water, and UF\&G: urban forest \& greenery

overall augmented by $42 \%$ from 1990 to 2020 (Table 6). The results also show that both the land-use intensity and the growth rate continued to increase from 1990 to 2020. The spatial distribution of LUI change during these study periods demonstrated significant consistency with ILUDD in Ethiopian cities (Fig. 7). Moreover, cities with rapid economic development in Ethiopia commonly have high input and high output on land, cities with higher LUI increases were mainly located in rapidly developing economic cities.

The high-value ecosystem of ILUDD was found in the urban center and then augmented to the north and southwest parts of Addis Ababa city. The northern part was dominated by urban forest and greenery, and the economic development was slower than that of other parts. Adama city that experienced higher ILUDD between the periods 1990-2020 was mainly distributed on the northeast and southeast parts also saw the rapid land-use change, mainly caused by rapid urbanization and expansion of industrial zones. Moreover, Bahir Dar city also saw a rapid land-use change with higher ILUDD were mainly located in central with the bi-fractured direction of the city (Fig. 8).

\section{Discussion}

Comparisons of spatial-temporal urban agglomeration and possible drivers

On account of rapid urbanization, large scale ruralurban population migrations, an illegal settlement in and around cities, and unplanned utilization of urban ecosystem have occurred since 1990, the urban ecosystems configuration and physical morphology are significantly changed in Ethiopia (Larsen et al. 2019; Terfa et al. 2019; Wubie et al. 2020). In addition, rapid economic development, and inconsistence reform, and implementation of urban land policy, have led to dynamics in the land use of cities of Ethiopia (Woldegerima et al. 2017; Kinfu et al. 2019; Bulti and Abebe 2020). Overall, LULC change in the urban ecosystem is strongly an anthropogenic-driven process (Peng et al. 2016; Mamat et al. 2018; Das and Das 2019). Notwithstanding the rapid urban agglomeration of study periods (1990-2020), the spatiotemporal configurations significantly varied among the cities of Bahir Dar, Addis Ababa, Adama, and Hawassa and within the cities. Specifically, the urban ecosystem of Addis Ababa augmented 2.4 times Adama, and 3.54 and 11.23 folding of Bahir Dar, and Hawassa cities respectively while that of Adama, Bahir Dar, and Hawassa cities augmented by $2.25 \%, 2.3 \%$, and $3.42 \%$, in that order. Additionally, 

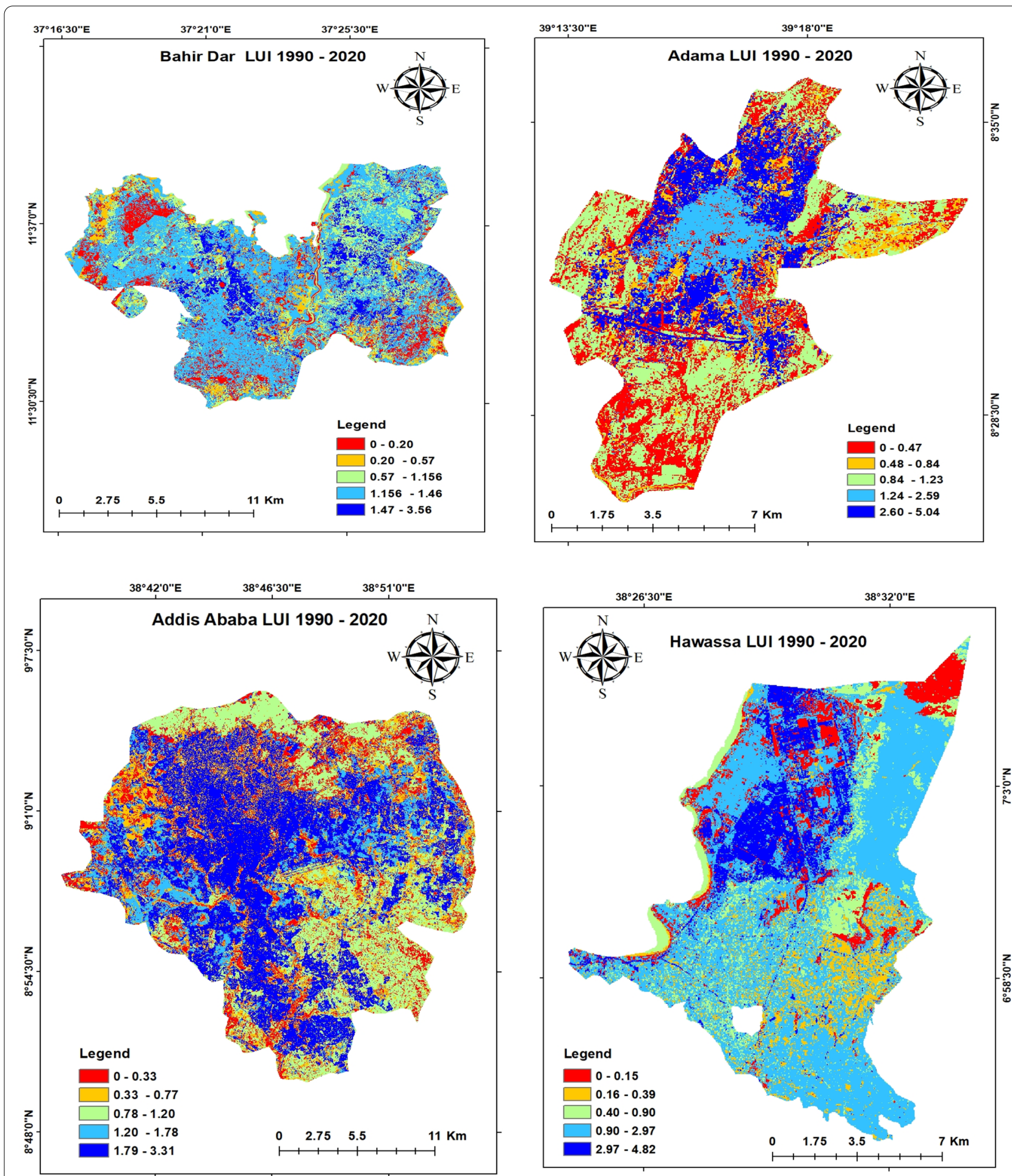

Fig. 7 The LUI of cities from 1990 to 2020

the direction, pattern, and location of urban spreading out in each city have been mainly connected with discrepancies in their illegal settlement in and around cities and unplanned utilization of urban ecosystem, administrative conditions, loopholes of the nation's land policy inter alia, and urban master plans (Kinfu et al. 2019; Larsen et al. 2019; Admasu et al. 2020; Bulti and Abebe 2020; Wubie et al. 2020). 

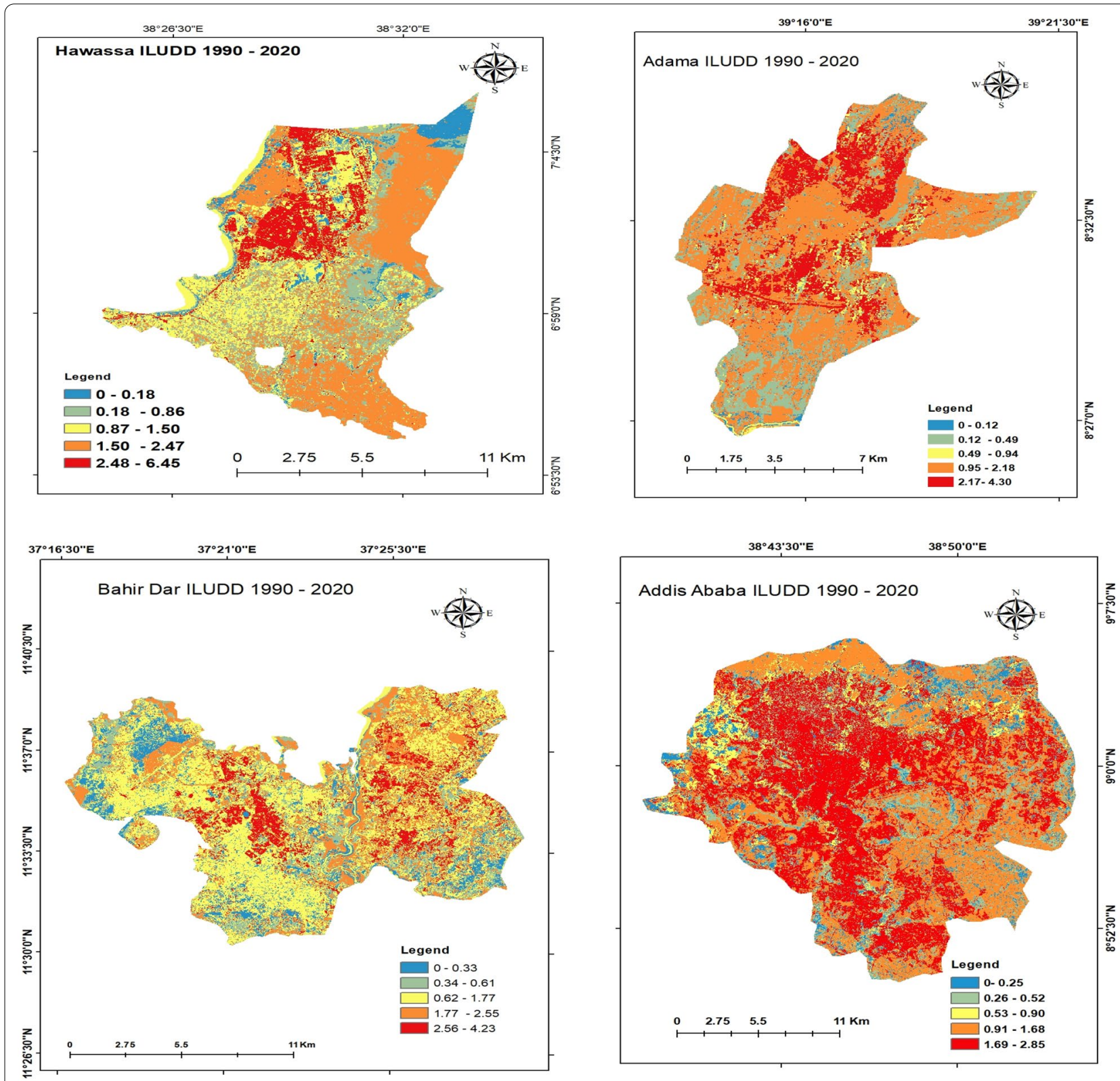

Fig. 8 The ILUDD of cities from 1990 to 2020

Overall, the present study confirmed that cities expanding horizontally with different intensities, land use diversity, and followed urban agriculture $\rightarrow$ bare land $\rightarrow$ urban forest and greenery $\rightarrow$ build up an ecosystem pattern of dynamics. For example, in the case of Addis Ababa, the presence of the Entoto Mountain in the northern part is limited to the outskirt pattern to the eastern, southern, and southwest directions (Figs. 7 and 8). While due to the appearance of lake Tanna and Abayi river the agglomeration of the Bahir Dar is fractured into two parts and shows an unpredicted pattern. Moreover, because of the existence of Lake Hawassa of the western, and Mountain in the south direction, the spreading out of Hawassa determined to the northeast, east, and southeast parts (Figs. 7 and 8). Conversely, in the case of Adama, because of the occurrence of the mountain along the east direction, the city expands towards north, northeast, and southwest directions (Figs. 7 and 8). The finding is coherent with the recent study in Addis Ababa (Larsen et al. 2019), Hawassa city (Kinfu et al. 2019), Adama (Bulti and Abebe 2020), and Bahir Dar (Wubie et al. 2020). While 
the priority of driving factors and urban growth pace inversely proportional to each other.

\section{Dynamics between land uses}

The result of this study exhibited that a significant slice of the landscapes in each city exposed to changes in land use and land covers. Built-up development, the most outstanding incident, is most related to large-scale deterioration in urban agricultural land. This is maybe happening as the result of secondary land use dynamics and shows a dissimilar trend in that, most studies reported built-up upsurge at the expense of urban forest ecosystem (Gashu and Gebre-Egziabher 2018; Kinfu et al. 2019; Larsen et al. 2019; Azagew and Worku 2020; Fitawok et al. 2020; Zou and Wang 2021). Moreover, the loss rate of urban forest and greenery was also high, mainly in ecosystems which are found as fragmented in around urban agricultural ecosystem and border area of the cities. Additionally, the transition of urban agriculture and/ or urban forest change was slightly varying before and after the first and second periods of study (Table 4). Earlier 1990 to 2000, urban agricultural/ forest land expansion into built-up had fast rate than 2000 to 2010 and had a very slow rate that of 2010 to 2020 (Larsen et al. 2019). In the final periods, the devastating increase of ecological land into built up to fulfill the need for housing and urban facilities for the residents. Overall, urban landscape transitions are multiple factored and irreversible dynamics.

\section{Urban ecosystem growth and direction}

Studying where active urbanization has to exists and at what pattern and orientations are very vital for ecological land management and resilience (Rimal et al. 2018, 2019; Bahers et al. 2019; Larsen et al. 2019). Since the city centers are mostly the active hub of socioeconomic and human-ecological land interaction. In the present work, city expansion started from the urban centers then rapidly expand to all directions of ecological land (Figs. 7 and 8). Additionally, the overall ILUDD analysis shows that all cities have positive expansion rates in all orientations with a concentration on the newly converted ecosystem (Table 3). Moreover, during the first phase of the study, the ILUDD was highest in Bahir Dar, Adama, and Hawassa cities. This shows that cities experienced rapid urban development, While, it was lowest in Addis Ababa city $(-0.36 \%)$. Later, the ILUDD negatively declined, and the city center-based orientations of urban growth were observed. This is possibly associated with the declining trend of socio-economic development of the country (Minta et al. 2018; Kinfu et al. 2019; Larsen et al.
2019; Bulti and Abebe 2020). Besides, LUI resalt shows the degree of the human interface on ecological land dynamics because intensity analysis shows the association between socioeconomic factors and the magnitude of impacts of each land-use type. Thus, the spatial distribution of LUI change during these study periods demonstrated significant consistency with ILUDD in Ethiopian cities (Fig. 7). Moreover, cities with rapid economic development in Ethiopia commonly have high input and high output on ecological land, cities with higher LUI increases were mainly located in rapidly developing economic cities (Huang et al. 2018; Shao et al. 2020).

\section{Implications for planning and sustainable development}

Our assessments of the dynamics of LULC change result play a significant role in the urban ecological land study providing empirical pieces of evidence that can work for cities resilient and sustainable development purposes. Additionally, it will serve as a baseline to compare and estimate the extent of urban landscape change, and open discussion during urban policy preparations, and indifferent features of intervention strategies for green city resilience. Besides, if the one applied the output of this work in other countries, it would be filling some gaps of existing literature and indicated the need for an integrated ecological land management approach to regulate human activities and restore previously degraded ecological land by following think globally and act locally approach.

\section{Conclusions}

The present study analyzed the dynamics between land and urbanization of four rapidly developing cities of Ethiopia from an economical value and spatial point of view. There were substantial dynamics in the urban to the built-up ecosystem of each city over the study period, and the overall magnitude of the spatial pattern was followed "urban agriculture $>$ urban forest and greenery $>$ open space $>$ built up" from urban agricultural to the multi-complex human-dominance ecosystem, with a significant influence on ecological land and ecosystem services provides. Moreover, the direction, pattern, and location of urban spreading out in each city have been mainly connected with discrepancies in their illegal settlement in and around cities and unplanned utilization of urban ecosystem, administrative conditions, loopholes of the nation's land policy inter alia, and urban master plans. Notwithstanding, the rapid urban agglomeration of study periods the spatiotemporal configurations significantly varied among 
the cities. In all cities, better use of existing ecological land resources needs a holistic land-use policy and strategic planning that ensure both economic and environmental benefits.

\section{Abbreviations}

ESs: Ecosystem services; ESV: Ecosystem serves valuation; LUD: Land-use diversity; LUI: Land-use diversity; ILUDD: Integrated land use a dynamic degree; LULC: Land use land cover; AA: Addis Ababa; BD: Bahir Dar; HW: Hawassa; AD: Adama; AGR: Annual Growth Rate.

\section{Acknowledgements}

The authors would like to thank Kotebe Metropolitan University and Addis Ababa University for their educational support. The authors also thank USGS (U.S. Geological Survey) for the free data availability and GeoDe and Google Earth pro Developers for the free software.

\section{Authors' contributions}

All authors equally contribute in designed, conducted reviews, analyzed the data, and drafted and writing manuscripts. All authors read and approved the final manuscript.

\section{Funding}

This research was not received any financially supported.

\section{Availability of data and materials}

The datasets analyzed during the current study are available from the corresponding author on reasonable request.

\section{Declarations}

Ethics approval and consent to participate

There is no ethical conflict.

\section{Consent for publication}

All authors read the manuscript and agreed to publication.

\section{Competing interests}

The authors declare that they have no competing interests.

\section{Author details}

${ }^{1}$ Kotebe Metropolitan University, Addis Ababa, Ethiopia. ${ }^{2}$ Center for Environmental Science, Addis Ababa University, Addis Ababa, Ethiopia.

Received: 22 February 2021 Accepted: 11 June 2021

Published online: 28 June 2021

\section{References}

Admasu WF, Boerema A, Nyssen J, Minale AS, Tsegaye EA, Van Passel S (2020) Uncovering ecosystem services of expropriated land: the case of urban expansion in Bahir Dar, Northwest Ethiopia. Land 9:395

Ahmed DA, Fawzy M, Saeed NM, Awad MA (2015) Effect of the recent land use on the plant diversity and community structure of Omayed Biosphere Reserve, Egypt. Glob Ecol Conserv 4:26-37

Alawamy JS, Balasundram SK, Hanif AHM, Sung CTBJS (2020) Detecting and analyzing land use and land cover changes in the region of Al-Jabal Al-Akhdar, Libya using time-series landsat data from 1985 to 2017. Sustainability $12: 4490$

Azagew S, Worku H (2020) Accessibility of urban green infrastructure in AddisAbaba city, Ethiopia: current status and future challenge. Environ Syst Res 9:1-20

Bahers JB, Barles S, Durand MJJ (2019) Urban metabolism of intermediate cities: the material flow analysis, hinterlands and the logistics-hub function of Rennes and Le Mans (France). J Ind Ecol 23:686-698
Bhat PA, Shafiq MU, Mir AA, Ahmed P (2017) Urban sprawl and its impact on landuse/land cover dynamics of Dehradun City, India. Int J Sustain Built Environ 6:513-521

Bulti DT, Abebe BG (2020) Analyzing the impacts of urbanization on runoff characteristics in Adama city, Ethiopia. SN Appl Sci 2:1-13

CAS (2007) Statistical abstract. Addis Ababa, Ethiopia, https://www.statsethiopia. gov.et/

CSA (2017) Statistical abstract. Addis Ababa, Ethiopia, https://www.statsethiopia. gov.et/

Chen W, Chi G, Li J (2019) The spatial association of ecosystem services with land use and land cover change at the county level in China, 1995-2015. Sci Total Environ 669:459-470

Chen S, Feng Y, Tong X, Liu S, Xie H, Gao C, Lei Z (2020) Modeling ESV losses caused by urban expansion using cellular automata and geographically weighted regression. Sci Tot Environ 712:136509

Chen L, Pei S, Liu X, Qiao Q, Liu C (2021) Mapping and analysing tradeoffs, synergies and losses among multiple ecosystem services across a transitional area in Beijing. China. Ecol Indic 123:107329

Chu L, Sun T, Wang T, Li Z, Cai C (2018) Evolution and prediction of landscape pattern and habitat quality based on CA-Markov and InVEST model in hubei section of three gorges reservoir area (TGRA). Sustainability 10:3854

Das S, Angadi DP (2020) Land use-land cover (LULC) transformation and its relation with land surface temperature changes: a case study of Barrackpore Subdivision, West Bengal, India. Remote Sens Appl Soc Environ 19:100322

Das M, Das A (2019) Dynamics of urbanization and its impact on urban ecosystem services (UESs): a study of a medium size town of West Bengal, Eastern India. J Urban Manage 8:420-434

Ethiopian Meteorology Agency (2012) National meteorological station report. Federal democratic republic of Ethiopia, Addis Ababa, http://www.ethio metmaprooms.gov.et/

Feyisa GL, Meilby H, Darrel Jenerette G, Pauliet S (2016) Locally optimized separability enhancement indices for urban land cover mapping: exploring thermal environmental consequences of rapid urbanization in Addis Ababa, Ethiopia. Remote Sens Environ 175:14-31

Feyissa G, Gebremariam E (2018) Mapping of landscape structure and forest cover change detection in the mountain chains around Addis Ababa: the case of Wechecha Mountain, Ethiopia. Remote Sens Appl Soc Environ 11:254-264

Fitawok MB, Derudder B, Minale AS, Van Passel S, Adgo E, Nyssen J (2020) Modeling the impact of urbanization on land-use change in Bahir Dar City, Ethiopia: an integrated cellular Automata-Markov Chain Approach. Land 9:115

Gashaw T, Tulu T, Argaw M, Worglul AW, Tolessa T, Kindu M (2018) Estimating the impacts of land use/land cover changes on Ecosystem Service Values: the case of the Andassa watershed in the Upper Blue Nile basin of Ethiopia. Ecosyst Serv 31:219-228

Gashu K, Gebre-Egziabher T (2018) Spatiotemporal trends of urban land use/land cover and green infrastructure change in two Ethiopian cities: Bahir Dar and Hawassa. Environ Syst Res 7:8

Gebrehiwot K, Teferi E, Woldu Z, Fekadu M, Desalegn T, Demissew S (2020) Dynamics and drivers of land cover change in the Afroalpine vegetation belt: Abune Yosef mountain range, Northern Ethiopia. Environment, Development and Sustainability:1-23.

Ha TV, Tuohy M, Irwin M, Tuan PV (2020) Monitoring and mapping rural urbanization and land use changes using Landsat data in the northeast subtropical region of Vietnam. Egypt J Remote Sens Space Sci 23:11-19

Hoque MZ, Cui S, Islam I, Xu L, Tang J (2020) Future impact of land use/land cover changes on ecosystem services in the lower Meghna River Estuary, Bangladesh. Sustainability 12:2112

Hu S, Chen L, Li L, Wang B, Yuan L, Cheng L, Yu Z, Zhang T (2019) Spatiotemporal dynamics of ecosystem service value determined by land-use changes in the urbanization of Anhui Province, China. Int J Environ Res Public Health 16:5104

Huang B, Huang J, Gilmore Pontius R, Tu Z (2018) Comparison of Intensity Analysis and the land use dynamic degrees to measure land changes outside versus inside the coastal zone of Longhai, China. Ecol Ind 89:336-347

Huang A, Xu Y, Sun P, Zhou G, Liu C, Lu L, Xiang Y, Wang H (2019) Land use/land cover changes and its impact on ecosystem services in ecologically fragile zone: a case study of Zhangjiakou City, Hebei Province, China. Ecol Ind 104:604-614 
Kindu M, Schneider T, Teketay D, Knoke T (2015) Drivers of land use/land cover changes in Munessa-Shashemene landscape of the south-central highlands of Ethiopia. Environ Monit Assess 187:452

Kindu M, Schneider T, Teketay D, Knoke T (2016) Changes of ecosystem service values in response to land use/land cover dynamics in MunessaShashemene landscape of the Ethiopian highlands. Sci Total Environ 547:137-147

Kinfu E, Bombeck H, Nigussie A, Wegayehu F (2019) The genesis of peri-urban Ethiopia: the case of Hawassa city. J Land Rural Stud 7:71-95

Larsen L, Yeshitela K, Mulatu T, Seifu S, Desta H (2019) The impact of rapid urbanization and public housing development on urban form and density in Addis Ababa. Ethiopia Land 8:66

Li Z, Sun Z, Tian Y, Zhong J, Yang W (2019) Impact of land use/cover change on Yangtze River Delta Urban Agglomeration ecosystem services value: temporal-spatial patterns and cold/hot spots ecosystem services value change brought by urbanization. Int J Environ Res Public Health 16:123

Li X, Stringer LC, Dallimer MJC (2021) The spatial and temporal characteristics of urban heat island intensity: implications for East Africa's Urban Development. Climate 9:51

Liu Y, Hou X, Li X, Song B, Wang C (2020b) Assessing and predicting changes in ecosystem service values based on land use/cover change in the Bohai Rim coastal zone. Ecol Indic 111:106004

Liu F, Zhang X, Murayama Y, Morimoto T (2020a) Impacts of land cover/use on the urban thermal environment: a comparative study of 10 megacities in China. Remote Sens 12:307

Lu D, Mausel P, Brondizio E, Moran EJI (2004) Change detection techniques. Int J Remote Sens 25:2365-2401

Mamat A, Halik Ü, Rouzi A (2018) Variations of ecosystem service value in response to land-use change in the Kashgar Region. Northwest China Sustain 10:200

Mekasha ST, Suryabhagavan K, Gebrehiwot M (2020) Geo-spatial approach for land-use and land-cover changes and deforestation mapping: a case study of Ankasha Guagusa, Northwestern, Ethiopia. Trop Ecol 61:550-569

Mekuriaw A, Cherinet M, Tsegaye L (2020) Assessing the impact of land cover changes on selected ecosystem services in upper Suha watershed, Gojjam, Ethiopia. Int J River Basin Manage. https://doi.org/10.1080/15715124.2019. 1704767

Meng L, Sun Y, Zhao S (2020) Comparing the spatial and temporal dynamics of urban expansion in Guangzhou and Shenzhen from 1975 to 2015: a case study of pioneer cities in China's rapid urbanization. Land Use Policy 97:104753

Minta M, Kibret K, Thorne P, Nigussie T, Nigatu L (2018) Land use and land cover dynamics in Dendi-Jeldu hilly-mountainous areas in the central Ethiopian highlands. Geoderma 314:27-36

Mohamed A, Worku H (2019) Quantification of the land use/land cover dynamics and the degree of urban growth goodness for sustainable urban land use planning in Addis Ababa and the surrounding Oromia special zone. J Urban Manage 8:145-158

Mohan M, Pathan SK, Narendrareddy K, Kandya A, Pandey SJJ (2011) Dynamics of urbanization and its impact on land-use/land-cover: a case study of megacity Delhi. J Environ Protect 2:1274

NMA (2020) National meteorological station report. Federal democratic republic of Ethiopia, Addis Ababa, http://www.ethiometmaprooms.gov.et/

Peng WF, Zhou JM, Fan SY, Yang CJ (2016) Effects of the land use change on ecosystem service value in Chengdu, western China from 1978 to 2010. J Indian Soc Remote Sens 44:197-206

Peng J, Zhao M, Guo X, Pan Y, Liu Y (2017) Spatial-temporal dynamics and associated driving forces of urban ecological land: a case study in Shenzhen City, China. Habitat Int 60:81-90

Rimal B, Zhang L, Keshtkar H, Haack BN, Rijal S, Zhang P (2018) Land use/land cover dynamics and modeling of urban land expansion by the integration of cellular automata and markov chain. ISPRS Int J Geo Inf 7:154

Rimal B, Sharma R, Kunwar R, Keshtkar H, Stork NE, Rijal S, Rahman SA, Baral H (2019) Effects of land use and land cover change on ecosystem services in the Koshi River Basin, Eastern Nepal. Ecosyst Serv 38:100963

Seto KC, Güneralp B, Hutyra LR (2012) Global forecasts of urban expansion to 2030 and direct impacts on biodiversity and carbon pools. Proc Natl Acad Sci 109:16083-16088
Shao Y, Yuan X, Ma C, Ma R, Ren Z (2020) Quantifying the spatial association between land use change and ecosystem services value: a case study in Xi'an, China. Sustainability 12:4449

Song W, Deng X (2017) Land-use/land-cover change and ecosystem service provision in China. Sci Total Environ 576:705-719

Story M, Congalton RG (1986) Accuracy assessment: a user's perspective. Photogramm Eng Remote Sens 52:397-399

Talukdar S, Singha P, Shahfahad S, Mahato BP, Rahman A (2020) Dynamics of ecosystem services (ESs) in response to land use land cover (LU/LC) changes in the lower Gangetic plain of India. Ecol Indic 112:106121

Temesgen H, Wu W, Shi X, Yirsaw E, Bekele B, Kindu M (2018) Variation in ecosystem service values in an agroforestry dominated landscape in ethiopia: implications for land use and conservation policy. Sustainability 10:1126

Terfa BK, Chen N, Liu D, Zhang X, Niyogi D (2019) Urban expansion in Ethiopia from 1987 to 2017: characteristics, spatial patterns, and driving forces. Sustainability 11:2973

Terfa BK, Chen N, Zhang X, Niyogi D (2020) Spatial configuration and extent explains the urban heat mitigation potential due to green spaces: analysis over Addis Ababa, Ethiopia. Remote Sens 12:2876

Tolessa T, Senbeta F, Kidane M (2017) The impact of land use/land cover change on ecosystem services in the central highlands of Ethiopia. Ecosyst Serv 23:47-54

Venkata Mohan S, Dahiya S, Amulya K, Katakojwala R, Vanitha TK (2019) Can circular bioeconomy be fueled by waste biorefineries - a closer look. Bioresource Technol Rep 7:100277

Viitanen J, Kingston R (2014) Smart cities and green growth: outsourcing democratic and environmental resilience to the global technology sector. Environ Plann A 46:803-819

Wangai PW, Burkhard B, Müller F (2019) Quantifying and mapping land use changes and regulating ecosystem service potentials in a data-scarce periurban region in Kenya. Ecosyst People 15:11-32

Woldegerima T, Yeshitela K, Lindley S (2017) Characterizing the urban environment through urban morphology types (UMTs) mapping and land surface cover analysis: the case of Addis Ababa, Ethiopia. Urban Ecosyst 20:245-263

Wu J (2013) Landscape sustainability science: ecosystem services and human well-being in changing landscapes. Landscape Ecol 28:999-1023

Wubie AM, de Vries WT, Alemie BK (2020) A socio-spatial analysis of land use dynamics and process of land intervention in the Peri-urban areas of Bahir Dar City. Land 9:445

Ye Y, Bryan BA, Zhang JE, Connor JD, Chen L, Qin Z et al (2018) Changes in land-use and ecosystem services in the Guangzhou-Foshan Metropolitan Area, China from 1990 to 2010: Implications for sustainability under rapid urbanization. Ecological Indicators 93:930-941

Yang X, Damen MCJ, van Zuidam RA (1999) Satellite remote sensing and GIS for the analysis of channel migration changes in the active Yellow River Delta, China. Int J Appl Earth Obs Geoinf 1:146-157

Yohannes H, Soromessa T, Argaw M, Dewan A (2020) Changes in landscape composition and configuration in the Beressa watershed, Blue Nile basin of Ethiopian Highlands: historical and future exploration. Heliyon 6:e04859

Yu Z, Yao Y, Yang G, Wang X, Vejre H (2019) Strong contribution of rapid urbanization and urban agglomeration development to regional thermal environment dynamics and evolution. For Ecol Manage 446:214-225

Zhang H, Chen B, Sun Z, Bao Z (2013) Landscape perception and recreation needs in urban green space in Fuyang, Hangzhou, China. Urban for Urban Green 12:44-52

Zhang Y, Liu Y, Zhang Y, Liu Y, Zhang G, Chen Y (2018) On the spatial relationship between ecosystem services and urbanization: a case study in Wuhan, China. Sci Total Environ 637-638:780-790

Zhao L, Fan X (2020) Effects of Land use changes on ecosystem service values: a case study in Guilin, China. Pol J Environ Stud 29:1483-1492

Zorrilla-Miras P, Palomo I, Gómez-Baggethun E, Martín-López B, Lomas PL, Montes C (2014) Effects of land-use change on wetland ecosystem services: a case study in the Doñana marshes (SW Spain). Landsc Urban Plan 122:160-174

Zou H, Wang XJS (2021) Progress and gaps in research on urban green space morphology: a review. Sustainability 13:1202

\section{Publisher's Note}

Springer Nature remains neutral with regard to jurisdictional claims in published maps and institutional affiliations. 